\title{
Mortality in patients with multiple sclerosis
}

Antonio Scalfari, MD

Volker Knappertz, MD

Gary Cutter, $\mathrm{PhD}$

Douglas S. Goodin, MD

Raymond Ashton, PGCE

George C. Ebers, MD

Correspondence to

Dr. Ebers:

george.ebers@ndcn.ox.ac.uk
Supplemental data at www.neurology.org

\section{ABSTRACT}

Mortality in patients with multiple sclerosis (MS) is significantly increased compared with the general population. Many questions concerning survival in MS are still unanswered due to the difficulty of comparing information collected at different times and in different geographic areas. The increasing incidence of MS, the improvement in care of the chronically disabled, and different methodologies may explain the lack of coherence among studies' results. Reported times to death from birth and from disease onset/diagnosis are highly variable. Patients older at onset or with primary progressive course have shorter survival; however, data on sex and mortality are contradictory. Changes in sex ratio in MS over time represent one possible explanation. MS is the main cause of death in $\geq 50 \%$ of patients and the incidence of deaths not due to MS varies among countries. Particularly, suicide is substantially increased in patients with MS, and, despite its varying incidence, mainly due to "cultural bias," it should be considered an MS-related cause of death. Recent results of the long-term follow-up study of interferon- $\beta-1 b$ demonstrated a significant reduction of mortality among treated patients. Notwithstanding its long latency, mortality is therefore an unambiguously valid long-term outcome in randomized controlled trials. It usefully combines the net impact of treatment efficacy on longevity and adverse events, which may reduce it. Neurology ${ }^{\circledR}$ 2013;81:184-192

\section{GLOSSARY}

EDR = excess death rate; IFN = interferon; $\mathbf{M H C}=$ major histocompatibility complex; $\mathbf{M S}=$ multiple sclerosis; $\mathbf{P P}=$ primary progressive; $\mathbf{R C T}=$ randomized clinical trial; $\mathbf{S M R}=$ standardized mortality ratio.

Although in multiple sclerosis (MS) the accumulation of severe disability in the long term is not strictly the immediate cause of death, patients with MS have a statistically significant increase in mortality compared with the general population, with a reduction of life expectancy of $7-14$ years. ${ }^{1-10} \mathrm{~A}$ number of large registries have been set up to collect longitudinal data on disease course (including mortality), leading to similar but not always consistent conclusions. In addition, larger databases containing information about the general population and many millions of patients have examined all-cause mortality from other conditions as well as among patients with MS (e.g., Premier Perspective database), helping to address some of the unanswered questions concerning survival in MS.

Patients with MS may die from causes not related to the disease. ${ }^{3-5,8,11-15}$ Nevertheless, for just over half, on average, MS is recorded on death certificates as the underlying cause of death. Survival is an endpoint with unrivaled face validity, but it is very late in the course and has never been considered a treatment outcome measure in MS. The subject of mortality in MS tends to be underemphasized by neurologists, as it is with many other chronic diseases, with appropriate priority focused on symptomatic treatment and disease-modifying therapies. Limited research has been performed on this aspect of the disease.

This review focuses on mortality trends in MS and causes of death in patients with MS, assessed from published studies, and will discuss the challenge of comparing findings from data collected at different times, in different geographic areas, and over varying time periods.

\footnotetext{
From the Centre of Neuroscience (A.S.), Division of Experimental Medicine, Department of Medicine, Imperial College, Hammersmith Hospital, London, UK; Department of Neurology (V.K.), Heinrich Heine University Düsseldorf, Düsseldorf, Germany; AstraZeneca-Medimmune (V.K.), Gaithersburg, MD; Section on Research Methods and Clinical Trials (G.C.), University of Alabama at Birmingham, Birmingham; Department of Neurology (D.S.G.), University of California, San Francisco; PAREXEL MMS (R.A.), West Sussex; and Nuffield Department of Clinical Neurosciences (G.E.), John Radcliffe Hospital, University of Oxford, Oxford, UK.

Go to Neurology.org for full disclosures. Funding information and disclosures deemed relevant by the authors, if any, are provided at the end of the article.
} 
ALL-CAUSE MORTALITY: TIME TRENDS AND VARIABILITY Many methods have been employed to assess mortality in MS. These include the classic survival analyses (Kaplan-Meier curves and Cox regression) or more demographic-based approaches using standardized mortality ratios (SMRs; the ratio of observed to expected number of deaths, using mortality in the general population) and excess death rates (EDRs; observed minus expected number of deaths per 1,000 person-years).

Survival analyses. Kaplan-Meier curves are nonparametric and take into account "censored" data (i.e., patient not reaching the endpoint). ${ }^{16} \mathrm{~A}$ disadvantage, however, is that only a few factors can be analyzed (i.e., dichotomous or categorical strata), and continuous variables cannot be handled without categorization. ${ }^{17}$ In addition, mistakes and distortions frequently arise in the display and interpretation of such survival plots. ${ }^{17}$ Cox regression analysis offers the possibility to assess the relationship between relative survival and several independent exploratory variables, and to model the time to a specific event based on the value for a given covariate. However, the key limitation is that the model requires rigid assumptions to represent time-varying effects. ${ }^{18}$ Often the predictive effect of the prognostic factors changes over time, which violates the proportional hazards assumption of the model. ${ }^{19}$

Survival analyses can assess mortality from birth (age at death), according to the lifespan 3 3,11,13,15,20,21 (table 1), or from onset or diagnosis of MS 3 -5,7-9,15,22-25 (table 2). Each method has advantages and disadvantages. By analyzing survival from birth, mortality can be readily compared with expected mortality in matched populationbased controls. In addition, caveats associated with difficulties due to diagnostic timing are not applicable as the time of diagnosis and onset is bypassed. The date at birth is both accurate and straightforward to obtain and in large groups should measure the impact of MS on survival in general. However, this measurement does not take into account the duration of MS. Indeed, time from onset or diagnosis to death allows better characterization of the type and course of the disease.

Standardized mortality ratios and excess death rates. Directly age-adjusted SMRs allow comparison of mortality with respect to the general population, eliminating the effect of differing age distributions. However, the relative ranks or rates observed will depend on the standard population chosen for comparison. Furthermore, although advantaged by the possibility of adjusting the analysis according to several factors (such as race or sex), directly age-adjusted SMRs are relatively unstable when based on small numbers of deaths. Indirectly age-adjusted SMRs may be more useful, as the variance is smaller and the estimated values more precise.

EDRs are computed as the difference between the observed death rates and the expected number of deaths based on age, sex, race, and other covariates. Although they are not constant and tend to vary with age, ${ }^{26}$ EDRs, better than SMRs, allow comparisons of excess mortality in different periods, after disease onset. ${ }^{3}$

Variability in mortality among cohorts. Times to death vary considerably among cohorts (table 2). An extensive review of natural history studies reported an overall average time to death, from MS onset, of 35 years, ranging from 24.5 years in Scotland to 45 years in New Zealand. ${ }^{27}$ Mortality trends may differ even between neighboring geographic areas; MS median survival in Norway (41 years) ${ }^{8}$ was 10 years longer compared to Denmark (31 years) ${ }^{28}$ (table 2). Differences in follow-up duration and sample sizes explain some of the large variability observed among studies (table 2). In addition, ascertainment may have increased and care of the chronically disabled has improved substantially, potentially explaining the reported shorter time from diagnosis to death among older studies. Also, before disease-modifying treatment was available, only details of the most severe cases were recorded, whereas currently there is more complete ascertainment, with milder cases being included. Furthermore,

Table 1 Kaplan-Meier survival analyses from birth: Age at death in patients with MS

\begin{tabular}{|c|c|c|c|}
\hline Study & Place & Mean age at death, $y$, by lifespan & Cohort/deceased, $n$ \\
\hline Phadke $(1987)^{15}$ & Scotland & $25-80^{a}$ & $216 / 216$ \\
\hline Koch-Henriksen et al. (1998) & Denmark & 58.4 & $6,068 / 6,068$ \\
\hline Ekestern and Lebhart (2004) ${ }^{20}$ & Austria & 57 & $2,469 / 2,469$ \\
\hline Redelings et al. (2006) ${ }^{13}$ & United States & 60.9 & $27,319 / 27,319$ \\
\hline Hirst et al. (2008) ${ }^{4}$ & Wales & 65.3 & $379 / 221$ \\
\hline Smestad et al. $(2009)^{3}$ & Norway & 64.0 (RRMS)/66.0 (PPMS) & $386 / 263$ \\
\hline Ragonese et al. (2010)21 & Sicily & 63 & $194 / 30$ \\
\hline Kingwell et al. (2012) ${ }^{9}$ & Canada & 76.7 (RRMS = 76.9/PPMS = 76.3) & 6,917/1,025 (784/236 \\
\hline
\end{tabular}

Abbreviations: MS = multiple sclerosis; PPMS = primary progressive multiple sclerosis; RRMS = relapsing-remitting multiple sclerosis.

${ }^{\text {a }}$ Range. 
Table 2 Kaplan-Meier survival analyses from onset or diagnosis: Time to death in patients with MS

\begin{tabular}{|c|c|c|c|}
\hline Study & $\begin{array}{l}\text { Cohort/ } \\
\text { deceased, } \mathrm{n}\end{array}$ & Mean age at onset, $y$ & $\begin{array}{l}\text { Survival time from onset } \\
\text { or diagnosis of MS, y }\end{array}$ \\
\hline Leibowitz et al. (1969) ${ }^{24}$ & $266 / 52$ & 32.6 & 17 \\
\hline Phadke $(1987)^{15}$ & $216 / 216$ & & 24.5 \\
\hline \multirow[t]{3}{*}{ Riise et al. $(1988)^{23}$} & $598 / 136$ & & Overall 27 \\
\hline & & $<35$ & 34.5 \\
\hline & & $\geq 35$ & 21.7 \\
\hline \multirow[t]{2}{*}{ Midgard et al. (1995) ${ }^{25}$} & $251 / 70$ & 33.6 & Men 21.3 (75th percentile) \\
\hline & & & Women 24.5 (75th percentile) \\
\hline \multirow[t]{3}{*}{ Wallin et al. $(2000)^{22}$} & $2,489 / 2,059$ & & White men 34 \\
\hline & & & Black men 30 \\
\hline & & & White women 43 \\
\hline \multirow[t]{3}{*}{ Bronnum-Hansen et al. (2004) } & $9,881 / 4,254$ & & Overall 31 \\
\hline & & 34.7 & Men 28 \\
\hline & & 34.1 & Women 33 \\
\hline \multirow[t]{5}{*}{ Grytten Torkildsen et al. (2008) } & $878 / 198$ & & Overall 41 \\
\hline & & Group 21-30 & 45 \\
\hline & & Group 51-60 & 23 \\
\hline & & & 43 (RRMS) \\
\hline & & & 26 (PPMS) \\
\hline Hirst et al. (2008) ${ }^{4}$ & $379 / 221$ & & 38 \\
\hline \multirow[t]{2}{*}{ Smestad et al. (2009) ${ }^{3}$} & $386 / 263$ & 27.3 (Alive at inclusion) & 35 \\
\hline & & 34.8 (Deceased at inclusion) & \\
\hline \multirow[t]{2}{*}{ Hader $(2010)^{7}$} & $150 / 105$ & 30.5 & 33 (Men) \\
\hline & & 28.4 & 38 (Women) \\
\hline Kingwell et al. (2012) ${ }^{9}$ & $6,917 / 1,025$ & 31 & 47.5 \\
\hline
\end{tabular}

Abbreviations: MS = multiple sclerosis; PPMS = primary progressive multiple sclerosis; RRMS = relapsing-remitting multiple sclerosis.

time from disease onset or diagnosis is often based on patient recall, introducing possible bias toward shorter survival from onset.

There has been some variability in mortality reported, even when SMRs are common endpoints (figure 1). This is due to the declining pattern of SMR when duration of follow-up increases, leading to a higher number of expected and observed deaths. ${ }^{3}$ In a study by Sumelahti et al., ${ }^{6}$ the overall mortality rate remained stable during the first 2 years after diagnosis (SMR 0.8); however, it became significantly higher (2.4) between 2 and 9.9 years and increased further (3.1) over 10 years. This is probably partially due to aging and increasing mortality in adults.

The increasing incidence of MS in many coun$\operatorname{tries}^{29}$ and the lengthening of lifespan in the healthy general population ${ }^{30}$ make comparisons difficult among datasets acquired over time. An appropriate reference population should provide adjustment for this effect. Comparison of results is further complicated by considerable variation of duration and time of the observation period among studies, both affecting mortality estimates. . $^{2-11,113-15,21,22,25,31}$ (table 3). For example, in serial studies from Denmark, average age at death was initially recorded as 51 years in 1950 and then as 60 years in $1993 .{ }^{11}$ Similarly, the EDR from MS has been reported to have decreased from approximately 12 deaths per 1,000 person-years between 1949 and 1958 to $<6$ between 1979 and $1988 .{ }^{32}$ Furthermore, in Austria, the median age at death due to MS increased by 2.9 years in women between 1970 and $2001 .^{20} \mathrm{Ob}$ servations from Manitoba, Canada, suggested that the age-adjusted prevalence of MS has increased year on year. ${ }^{33}$ However, this is improbably attributed solely to prolonged survival (see Orton et al. ${ }^{29}$ ) and there may be additional factors.

FACTORS AFFECTING MORTALITY Survival is affected by several factors. It is well established that a primary progressive (PP) course associates with faster time to

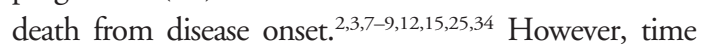
to death from birth is not significantly affected by type 
Figure 1 Standardized mortality ratios for all causes of mortality

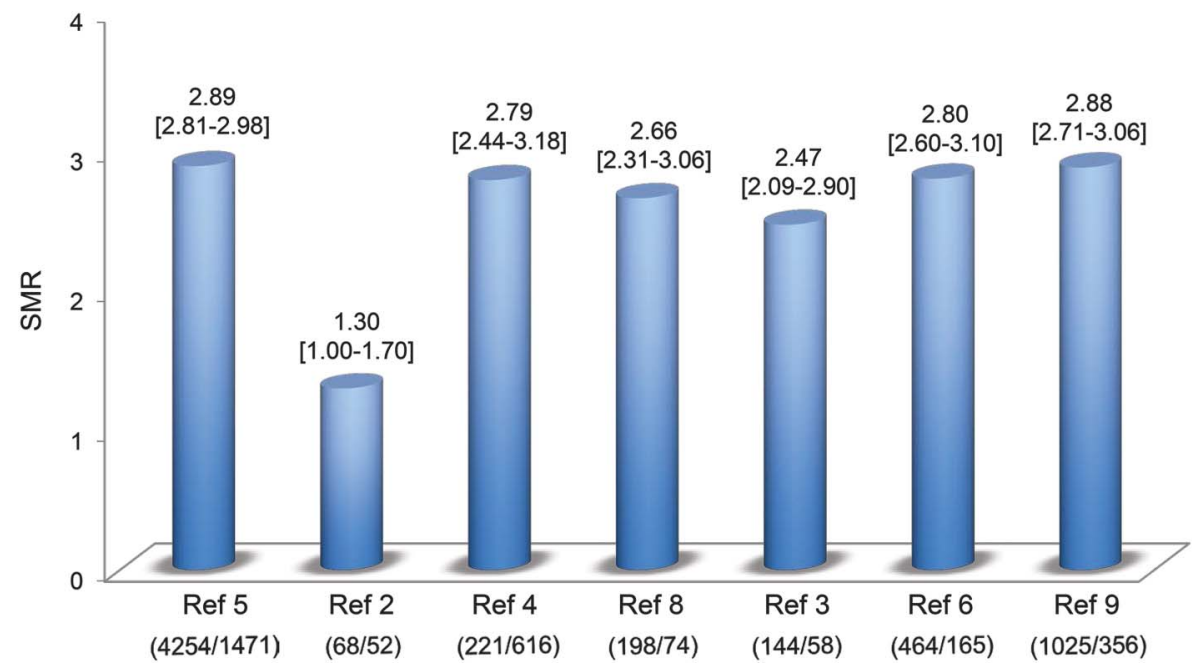

For each study, number of observed deaths/number of expected deaths in the matched general population is indicated in brackets. SMR = standardized mortality ratio.

of disease course. Similar median/mean ages at death have been reported between patients with PP and relapsingremitting onset: 78 vs 78 median years, ${ }^{35} 68$ vs 66 median years, ${ }^{3} 76.3$ vs 76.9 mean years. ${ }^{9}$ A majority of studies found an association between younger age at onset and longer survival or lower risk of death. 2,3,7-9,12,35 $\mathrm{Nev}-$ ertheless, age at onset of $\mathrm{PP}^{35,36}$ and age at onset of secondary progressive phase $\mathrm{e}^{35}$ do not affect time to death from the onset of progression. Data on the prognostic effect of type of initial symptoms also do not seem homogenous. Groups with brainstem/cerebellar involvement at onset have been reported to have shorter ${ }^{15,25}$ or even longer ${ }^{3}$ survival. Others found no impact of initial presentation on time to, and probability of, death. ${ }^{2}$

SEX AND MORTALITY There are contradicting data about the relationship between sex and mortality. Although many studies found longer survival in female groups, $, 7-9,15,25$ others reported no difference between men and women, ${ }^{3,7,12}$ or even a higher risk of mortality

Table 3 Duration of follow-up among studies of mortality in patients with multiple sclerosis (MS)

\begin{tabular}{|c|c|c|c|c|}
\hline Phadke $(1987)^{15}$ & Scotland & $1970-1980$ & 10 & $216 / 216$ \\
\hline Sadnovnick et al. (1991) ${ }^{14}$ & Canada & $1972-1988$ & 16 & $3,126 / 145$ \\
\hline Midgard et al. $(1995)^{25}$ & Norway & $1950-1984$ & 34 & $251 / 70$ \\
\hline Wallin et al. $(2000)^{22}$ & United States & 1956-1996 & 40 & $2,489 / 2,059$ \\
\hline Bronnum-Hansen et al. $(2004)^{5}$ & Denmark & $1949-2000$ & 51 & $9,881 / 4,254$ \\
\hline Redelings et al. $(2006)^{13}$ & United States & $1990-2001$ & 11 & $27,319 / 27,319$ \\
\hline Smestad et al. $(2009)^{3}$ & Norway & $1940-2006$ & 66 & $386 / 263$ \\
\hline Ebers et al. (2009) ${ }^{31, a}$ & United States/Canada & 1988-2005 & 16 & $372 / 35$ \\
\hline Sumelahti et al. $(2010)^{6}$ & Finland & $1971-2006$ & 36 & $1,595 / 464$ \\
\hline Ragonese et al. $(2010)^{21}$ & Sicily & 1981-2001 & 20 & $194 / 30$ \\
\hline Hader $(2010)^{7}$ & Canada & 1977-2007 & 30 & $150 / 105$ \\
\hline Kingwell et al. (2012)9 & Canada & 1980-2005 & 25 & $6,917 / 1,025$ \\
\hline
\end{tabular}

${ }^{a}$ Long-term follow-up of randomized clinical trial. 
among female patients. ${ }^{20,21}$ Lack of homogeneity could be partially attributed to changes of MS sex ratio over time. The higher incidence of MS among women observed for the last 4-5 decades was not evident 3-4 generations ago, when sex ratio was close to unity. ${ }^{29}$ Recent studies have shown that the sex ratio in MS is still changing in many countries. For instance, in Japan the female-to-male ratio has increased from 1.7 in 1972 to 2.9 in $2004^{37}$; in northern climates it now exceeds $3.1{ }^{38,39}$ In addition, the increased concordance rate in monozygotic twins compared with dizygotic twins or siblings is very largely derived from female pairs. ${ }^{40}$ The causes of the sex ratio changes that have occurred in most countries are unclear but are likely to have resulted from environmental influences or from the consequences of gene-environmental interactions. Since epigenetic mechanisms are implied, it is probable that this will be a key way genes and the environment interact. A recent study investigating the sex effects in parental transmission of major histocompatibility complex (MHC) class II alleles reported that haplotype-specific epigenetic changes at MHC class II and their decay appear to be important in MS pathogenesis and inheritance of risk. ${ }^{41}$

Figure 2 Percentages of deaths due to multiple sclerosis (MS) among studies

Ref

6

$\mathrm{N}$ of deaths $=464$

$58.0 \%$ $42.0 \%$

3

\section{$50.0 \%$}

$\mathrm{N}$ of deaths $=263$

8

\section{$56.0 \%$}

$\mathrm{N}$ of deaths $=198$ $57.0 \%$

$\mathrm{N}$ of deaths $=221$

\begin{tabular}{|c|c|c|}
\hline \multicolumn{3}{|c|}{$\mathrm{N}$ of deaths $=68$} \\
\hline 2 & $75.0 \%$ & $25.0 \%$ \\
\hline \multicolumn{3}{|c|}{$\mathrm{N}$ of deaths $=27,319$} \\
\hline 13 & $61.0 \%$ & $39.0 \%$ \\
\hline \multicolumn{3}{|c|}{$\mathrm{N}$ of deaths $=4254$} \\
\hline 5 & $\mathbf{5 6 . 0} \%$ & $44.0 \%$ \\
\hline \multicolumn{3}{|c|}{$\mathrm{N}$ of deaths $=6068$} \\
\hline 11 & $\mathbf{5 5 . 0} \%$ & $45.0 \%$ \\
\hline \multicolumn{3}{|c|}{$\mathrm{N}$ of deaths $=216$} \\
\hline 15 & $62.0 \%$ & $38.0 \%$ \\
\hline \multicolumn{3}{|c|}{$\mathrm{N}$ of deaths $=145$} \\
\hline 14 & $47.1 \%$ & $52.9 \%$ \\
\hline
\end{tabular}

CAUSES OF DEATH IN MS Although MS is essentially chronic and disabling, long-term disability is not necessarily the immediate cause of death. However, MS does carry the risk of systemic complications in the advanced stages of the disease that may lead to death. The record of "MS" as main cause of death marks the attainment of the last step of the Expanded Disability Status Scale (EDSS 10), defined as "...an acute death due to brainstem involvement or to respiratory failure or death consequent to the chronic bedridden state with terminal pneumonia, sepsis, uremia, cardiorespiratory failure. It excludes intercurrent causes of death. Antemortem, the patient will ordinary be DSS 9, sometimes $8 .{ }^{.42}$

This definition can be variably interpreted by doctors and be entirely unknown for those not familiar with MS, leading to large variation of the proportion of "deaths due to MS" among cohorts. This ranges from the lowest 50\% in the Norwegian cohort ${ }^{3}$ and $47 \%$ in the Canadian cohort $^{14}$ to the highest $75 \%$ recorded in the French cohort $^{2}$ (figure 2). Deaths not related to MS are mainly attributable to the common causes of death in the nonMS population: cardiovascular disease, cancer, infectious and respiratory disease, and accidents or suicide ${ }^{3-5,8,11-15}$ (table 4). The incidence of these causes of death varies greatly among studies. Cardiovascular diseases were responsible for $14.4 \%^{3}$ and $13.1 \%^{8}$ of mortality cases in 2 populations of Norwegian MS cohorts, but for as many as $26 \%$ in a Finnish MS population. ${ }^{12}$ However, deaths due to cardiovascular disease depend heavily on the age distribution of those at risk. The Finnish study also demonstrated a higher proportion of MS deaths related to cancer $(35 \%)^{12}$ compared with cohorts from Denmark (8.6\% and 10.1\%), ${ }^{5,11}$ Wales $(9.5 \%),{ }^{43}$ and Norway $(9.8 \%$ and $10.6 \%),{ }^{3,8}$ again possibly due to age differences. Interestingly, there seems to be contradicting data on the frequency of cancer among patients with MS compared with the matched general population. A lower incidence was observed in Denmark (SMR $=0.85$ and $0.79)^{5,11}$ and Canada $(0.67 \mathrm{x}),{ }^{14}$ and a higher incidence was observed in Finland (35\% vs 20\%) ${ }^{12}$ and Norway $(\mathrm{SMR}=2.25) .{ }^{8}$ Other studies, aimed at addressing this specific question, could not find cohering results, demonstrating similar ${ }^{43,44}$ or lower risk ${ }^{45,46}$ of cancer among patients with MS. A recent meta-analysis, pooling data from several cohorts and gathering information from more than 45,000 patients, concluded there is a significantly decreased risk (odds ratio $=0.92 ; p=0.004$ ) of all cancers in the MS population relative to controls, ${ }^{47}$ which could be due to earlier death since the risk of cancer rises with age. Respiratory diseases not attributed to MS-related disability generally account for a low percentage of deaths, ranging from $1.5 \%$ among Norwegian patients $^{3}$ to $4.7 \%$ in Danish patients ${ }^{5}$ and $5.4 \%$ in Finnish patients. ${ }^{6}$ In striking contrast with the general trend, $47.5 \%$ of deaths in Welsh patients were attributed to respiratory diseases (infections included), ${ }^{4}$ and surely this 
Table 4 Main causes of death among patients with multiple sclerosis (MS)

\begin{tabular}{|c|c|c|c|c|c|c|c|c|c|}
\hline & $\begin{array}{l}\text { Phadke } \\
(1987)^{15}\end{array}$ & $\begin{array}{l}\text { Sadovnick } \\
\text { et al. }(1991)^{14}\end{array}$ & $\begin{array}{l}\text { Koch-Henriksen } \\
\text { et al. }(1998)^{11}\end{array}$ & $\begin{array}{l}\text { Sumelahti } \\
\text { et al. }(2002)^{12}\end{array}$ & $\begin{array}{l}\text { Bronnum-Hansen } \\
\text { et al. }(2004)^{5}\end{array}$ & $\begin{array}{l}\text { Redelings } \\
\text { et al. }(2006)^{13}\end{array}$ & $\begin{array}{l}\text { Grytten Torkildsen } \\
\text { et al. }(2008)^{8}\end{array}$ & $\begin{array}{l}\text { Hirst et al. } \\
(2008)^{4}\end{array}$ & $\begin{array}{l}\text { Smestad } \\
\text { et al. }(2009)^{3}\end{array}$ \\
\hline No. of deaths & 216 & 145 & 6,068 & 219 & 4,254 & 27,319 & 198 & 221 & 263 \\
\hline \multicolumn{10}{|c|}{ Causes of death, \% } \\
\hline MS & 62.0 & 47.1 & 55.4 & 58.0 & 56.4 & 61.2 & 56.5 & 57.9 & 50.0 \\
\hline $\begin{array}{l}\text { Cardiovascular } \\
\text { disease }\end{array}$ & 19.0 & 20.6 & 17.6 & 26.0 & 15.5 & 10.9 & 13.1 & 16.0 & 14.4 \\
\hline Cancer & 12.0 & 30.2 & 8.6 & 35.0 & 10.1 & 8.5 & 10.6 & 9.5 & 9.8 \\
\hline $\begin{array}{l}\text { Respiratory } \\
\text { disease }\end{array}$ & 3.2 & II & 5.1 & /I & 4.7 & 19.7 & 5.1 & 47.5 & 1.5 \\
\hline $\begin{array}{l}\text { Accident/ } \\
\text { suicide }\end{array}$ & /I & 28.6 & 3.8 & 5.0 & 4.5 & 0.3 & 2.5 & 0.0 & 5.3 \\
\hline Other/unknown & 2.7 & /I & 9.5 & /I & 13.5 & /l & 6.6 & 8.6 & /l \\
\hline
\end{tabular}

has more to do with definition and local custom than to real difference in cause of death.

Causes of death and methodologic difficulties. The differences among recorded causes of death (table 4) can be attributed to methodologic differences, but there are other potential factors. The assessment of causes of death in population studies of MS is inevitably incomplete and rarely autopsy-confirmed. Most often it comes from death certificates or death registries but some large clinics do have capacity to have more proximate information. However, even here, the majority of deaths may lack clear documentation and often occur outside of treatment hospital settings. Although death certificates are the main source of information on the cause of death, other methods are available. Searches using both public domain, such as medical records, and private sources can be undertaken. Furthermore, MS experts can review patient charts and telephone contact and in-person interviews with relatives can be conducted. In the United States, mortality status can also be determined using the National Death Index. If related to a clinical trial, notes to file by investigators and data from the trial can also be checked. Given the potential for ambiguity in death certificates, one recent study used a blinded independent committee to determine if the cause of death in the original $\beta$-interferon (IFN) study was attributable to MS. ${ }^{48}$ There was a degree of inference involved but if a young bedridden patient dies of pneumonia it seems reasonable to conclude this was MS-related. This reality should not detract from the importance of carrying out studies of long-term outcome in trials and death is always a hard measure of potential adverse events.

The distribution of causes of death is strongly influenced by the age of the study population and coding practices, ${ }^{3}$ hindering accurate comparison of cause-specific mortality. There may also be cultural differences and potential problems associated with consistency of recording cause of death. In addition, completeness of ascertainment might influence the findings. The almost complete ascertainment of benign cases, where MS diagnosis is not obvious at death and may be overshadowed by an independent cause, could lead to a lower frequency of MS on death certificates. However, cause of death generally based on clinical examination and assessed by doctors with limited knowledge of the patient history ${ }^{11,12}$ has given results similar to studies using more specialized methods. In addition, similarly to other chronic diseases, the assessment of causes of death in MS can be greatly affected by the interval between patients' death and data collection.

Suicide. The risk of suicide among patients with MS has been reported to be increased compared with the general population: $\mathrm{SMR}=2.3,{ }^{49} \mathrm{SMR}=2.1,{ }^{50} \mathrm{SMR}=$ $1.62,{ }^{11} 7.5 \times{ }^{14}$ However, assessing its prevalence is particularly challenging, and widely varying incidence rates are found in the literature (table 4), exemplifying cultural biases existing in different populations: $28.6 \%,{ }^{14} 5 \%,{ }^{12}$ $5.3 \%,{ }^{3} 4.5 \%,{ }^{5} 3.8 \%,{ }^{11} 2.5 \%{ }^{8}$ Part of this variation results from referral bias due to the fact that clinic-based cohorts tend to include more severely affected individuals, with higher rates of affective disorders. ${ }^{4}$ Furthermore, considerable geographical and ethnic variation in general population suicide rates is apparent. It is also plausible that the cause of death recorded on the death certificate may be influenced by cultural taboos such as the right to be buried in certain cemeteries (cultural bias), so suicide may be underreported to avoid social stigma or to maintain insurance benefits. In Finland, where suicide rates in the general population are very high, suicides are not traditionally disguised or recorded as "accidents," and there are no obvious cultural or religious factors that would lead to underreporting. ${ }^{6}$ Indeed, the SMR for suicides (1.7) in Finnish patients with MS was not significantly increased compared with the general population. $^{6}$ On the contrary, substantially higher (7.5x) incidence is seen in longitudinally followed patients from 
Canada, where suicide tends to be underreported for cultural bias. ${ }^{14}$ However, suspected suicide in a patient with MS may be more comfortably ascribed to MS everywhere. Our view is that there is no reasonable doubt that suicide is substantially increased in MS and that suicide should be included as an MS-related cause of death, unless there is a case-specific reason to think otherwise. We have had patients surviving motor vehicle accidents following which they later admitted they had driven directly at obstacles with suicidal intent. Indeed, what presents as accidental deaths (e.g., car accidents, drowning) among patients with MS might have been driven by suicidal intention, affecting the reported number of suicides toward underestimation.

NATURAL HISTORY DATA VS CLINICAL TRIAL DATA IN THE ASSESSMENT OF MORTALITY There are limitations in the data obtained from randomized clinical trials (RCTs) ${ }^{31}$ and from natural history studies with respect to mortality as an outcome in MS. Due to substantial variability of the disease course, natural history studies require a large number of patients, a very long follow-up, and a low rate of dropouts. Such studies can be prone to migration, selection, and compliance biases $^{27}$ and very few have been conducted in subcategories of disease. Differences in data collection methodologies, sample sizes, number of losses to follow-up, and choices of endpoints explain the wide range of results reported in literature. ${ }^{51}$ In contrast, within clinical trial settings, patients' characteristics are carefully controlled and follow-up is regular with frequent assessments. However, the outcomes used are fragile and their surrogacy for long-term disease evolution has never been validated. ${ }^{52-54}$ In addition, patients are generally observed over a short period of time (usually no more than 2 years) and, since they tend to be young and mobile, it is hard to conduct an RCT for longer than 5 years. The length of time needed in order to confidently detect a treatment effect on disability in MS is probably several years or even longer when mortality is used as outcome. However, a more accurate selection of the study population may increase statistical power in future RCTs.

Clinical trial data must be adjusted when extrapolating to natural history studies for meaningful comparisons to be made. In an attempt to overcome the short trial duration, a number of long-term follow-up studies have been reported. ${ }^{31,55-59}$ Both 16-year ${ }^{31,56,57}$ and 21-year followup $^{48}$ studies of the pivotal IFN- $\beta$ - $1 \mathrm{~b}$ trial provide useful information on all-cause mortality that could not be obtained during the original investigation. In particular, the 21-year study had very high ascertainment $(98.4 \%)$ and showed a significant $(p=0.0173)$ reduction in all-cause mortality in patients originally randomized to IFN- $\beta-1 b$ $250 \mu \mathrm{g}$ compared with placebo (hazard ratio $=0.532$ [95\% confidence interval $0.314-0.902]$ ) (figure e- 1 on the Neurology ${ }^{\circledR}$ Web site at www.neurology.org) ${ }^{48}$ However, the missing data between when the patients were last observed in the trial and their time of death represent a main limitation, especially for characterizing the clinical course over time before death. In addition, patients included in the trial are not representative of the entire MS population, making it difficult to draw definitive conclusions on the real impact of disease-modifying therapy on patient mortality.

DISCUSSION Data from numerous large cohort registries confirmed that life expectancy in the MS population is reduced by 7 to 14 years compared with the general, healthy population. At least $50 \%$ of patients die from MS directly related causes. Nevertheless, survival of patients with MS is now much improved compared with a generation ago. Following successful efforts to increase longevity, the main problem now arises from high levels of disability maintained for prolonged time and consequently from the larger number of disabled patients needing to receive appropriate care.

Although a large amount of data on mortality has been gathered over the last 40 years, the lifespan of the general population is increasing and the care of chronically disabled patients has improved consistently, making comparison of datasets acquired over time problematic. In addition, the improvement of methodology and the increased duration of follow-up in recent studies, accounting for the large variability of mortality observed, make the task of reaching meaningful conclusions even harder. A possible way to overcome these difficulties and try to address appropriately the many unanswered questions on mortality is to calculate the reduced lifespan compared with the appropriate controls in the appropriate general population. In the future, it will be important to be able to assess the inherent strengths and weaknesses of each approach, and to standardize the way we collect data on mortality and causes of death, in order to make comparisons among studies more easily accessible.

Survival still represents a poorly described aspect of the disease, largely avoided by MS neurologists. It has never been used as an outcome measure when assessing the effect of treatments, although data from long-term follow-up clinical trials have recently highlighted its importance. The use of all-cause mortality as a long-term outcome measure in patients with MS has advantages. It eliminates the need to differentiate among specific causes (e.g., accidents, suicide, and medication-related mortality). In addition, it is not dependent on the frequently limited ability of the doctor to decide on a specific cause, and it simultaneously takes into account any deleterious effect on survival from treatment. Finally, it allows detection of whether the benefit of an immunosuppressive drug is offset by increased death from infection or cancer. We believe that the long latency of mortality as an outcome is offset to a degree by its unambiguous face validity. It therefore represents an attractive long-term 
endpoint for MS RCTs, usefully combining the net impact of treatment efficacy and adverse events.

\section{AUTHOR CONTRIBUTIONS}

Antonio Scalfari: critical revision of the manuscript for intellectual content Volker Knappertz: study concept and design, acquisition of data. Gary Cutter: critical revision of the manuscript for intellectual content. Douglas S. Goodin: critical revision of the manuscript for intellectual content. Raymond Ashton: critical revision of the manuscript for intellectual content. George C. Ebers: study concept and design, acquisition of data.

\section{ACKNOWLEDGMENT}

Copyediting was undertaken by Bari Samson, PAREXEL MMS, and was funded by Bayer HealthCare Pharmaceuticals.

\section{STUDY FUNDING}

No targeted funding reported.

\section{DISCLOSURE}

A. Scalfari reports no disclosures. V. Knappertz is a full-time employee of AstraZeneca and holds stock and stock options in the company. G. Cutter participates on Data and Safety Monitoring Committees for Apotek, Biogen-Idec, Cleveland Clinic, Glaxo Smith Klein Pharmaceuticals, Gilead Pharmaceuticals, Modigenetech/Prolor, Merck/Ono Pharmaceuticals, Merck, Neuren, Revalesio, Sanofi-Aventis, Teva, Vivus, NHLBI (Protocol Review Committee), National Institute of Neurological Disorders and Stroke, NMSS, and NICHD (OPRU oversight committee); has served as a consultant/on advisory boards/and received speaker honoraria from Alexion, Allozyne, Bayer, Celgene, Coronado Biosciences, Consortium of MS Centers (grant), Diogenix, Klein-Buendel Incorporated, Medimmune, Novartis, Nuron Biotech, Receptos, Spiniflex Pharmaceuticals, and Teva pharmaceuticals; and is employed by the University of Alabama at Birmingham and President of Pythagoras, Inc., a private consulting company located in Birmingham. D.S. Goodin has participated (or is currently participating) in several industry-sponsored clinical trials in MS. The sponsoring pharmaceutical companies for these trials have included (or do include) Ares-Serono, Merck-Serono, Novartis, Berlex Laboratories, BayerSchering Healthcare, Biogen-Idec, Schering AG, and Teva Neuroscience. He has also lectured at both medical conferences and in public on various aspects of the epidemiology, diagnosis, and management of MS. In many cases, these talks have been sponsored directly or indirectly by one or another of the above listed companies. He has also served as a temporary ad hoc consultant to several of these organizations on several occasions. R. Ashton is a salaried employee of PAREX EL MMS. G. Ebers has been a consultant for Bayer HealthCare and has received funding for research into the natural history of MS from Bayer HealthCare. He has served on a Data Monitoring committee for MedImmune, has had travel funded by EMD Serono, has received honoraria for speaking at meetings from EMD Serono, Danone, and Merck. Go to Neurology.org for full disclosures.

Received October 30, 2012. Accepted in final form March 26, 2013.

\section{REFERENCES}

1. Ragonese P, Aridon P, Salemi G, D'Amelio M, Savettieri G. Mortality in multiple sclerosis: a review. Eur J Neurol 2008;15: 123-127.

2. Leray E, Morrissey SP, Yaouanq J, et al. Long-term survival of patients with multiple sclerosis in West France. Mult Scler 2007;13:865-874.

3. Smestad C, Sandvik L, Celius EG. Excess mortality and cause of death in a cohort of Norwegian multiple sclerosis patients. Mult Scler 2009;15:1263-1270.

4. Hirst C, Swingler R, Compston DA, Ben-Shlomo Y, Robertson NP. Survival and cause of death in multiple sclerosis: a prospective population-based study. J Neurol Neurosurg Psychiatry 2008;79:1016-1021.
5. Bronnum-Hansen H, Koch-Henriksen N, Stenager E. Trends in survival and cause of death in Danish patients with multiple sclerosis. Brain 2004;127:844-850.

6. Sumelahti ML, Hakama M, Elovaara I, Pukkala E. Causes of death among patients with multiple sclerosis. Mult Scler 2010;16:1437-1442.

7. Hader WJ. Disability and survival of multiple sclerosis in Saskatoon, Saskatchewan. Can J Neurol Sci 2010;37:28-35.

8. Grytten Torkildsen N, Lie SA, Aarseth JH, Nyland H, Myhr KM. Survival and cause of death in multiple sclerosis: results from a 50-year follow-up in Western Norway. Mult Scler 2008;14:1191-1198.

9. Kingwell E, van der Kop M, Zhao Y, et al. Relative mortality and survival in multiple sclerosis: findings from British Columbia, Canada. J Neurol Neurosurg Psychiatry 2012;83:61-66.

10. Evans C, Tam J, Kingwell E, Oger J, Tremlett H. Long-term persistence with the immunomodulatory drugs for multiple sclerosis: a retrospective database study. Clin Ther 2012;34: 341-350.

11. Koch-Henriksen N, Bronnum-Hansen H, Stenager E. Underlying cause of death in Danish patients with multiple sclerosis: results from the Danish Multiple Sclerosis Registry. J Neurol Neurosurg Psychiatry 1998;65: 56-59.

12. Sumelahti ML, Tienari PJ, Wikstrom J, Salminen TM, Hakama M. Survival of multiple sclerosis in Finland between 1964 and 1993. Mult Scler 2002;8:350-355.

13. Redelings MD, McCoy L, Sorvillo F. Multiple sclerosis mortality and patterns of comorbidity in the United States from 1990 to 2001. Neuroepidemiology 2006;26:102-107.

14. Sadovnick AD, Eisen K, Ebers GC, Paty DW. Cause of death in patients attending multiple sclerosis clinics. Neurology 1991;41:1193-1196.

15. Phadke JG. Survival pattern and cause of death in patients with multiple sclerosis: results from an epidemiological survey in north east Scotland. J Neurol Neurosurg Psychiatry 1987;50:523-531.

16. Wittes J. Times to event: why are they hard to visualize?. J Natl Cancer Inst 2008;100:80-81.

17. Bollschweiler E. Benefits and limitations of Kaplan-Meier calculations of survival chance in cancer surgery. Langenbecks Arch Surg 2003;388:239-244.

18. Cortese G, Scheike TH, Martinussen T. Flexible survival regression modelling. Stat Methods Med Res 2010;19:5-28.

19. Schemper M, Wakounig S, Heinze G. The estimation of average hazard ratios by weighted Cox regression. Stat Med 2009;28:2473-2489.

20. Ekestern E, Lebhart G. Mortality from multiple sclerosis in Austria 1970-2001: dynamics, trends, and prospects. Eur J Neurol 2004;11:511-520.

21. Ragonese P, Aridon P, Mazzola MA, et al. Multiple sclerosis survival: a population-based study in Sicily. Eur J Neurol 2010;17:391-397.

22. Wallin MT, Page WF, Kurtzke JF. Epidemiology of multiple sclerosis in US veterans. VIII. Long-term survival after onset of multiple sclerosis. Brain 2000;123:1677-1687.

23. Riise T, Gronning M, Aarli JA, Nyland H, Larsen JP, Edland A. Prognostic factors for life expectancy in multiple sclerosis analysed by Cox-models. J Clin Epidemiol 1988;41: 1031-1036

24. Leibowitz U, Kahana E, Alter M. Survival and death in multiple sclerosis. Brain 1969;92:115-130.

25. Midgard R, Albrektsen G, Riise T, Kvale G, Nyland H. Prognostic factors for survival in multiple sclerosis: a 
longitudinal, population based study in More and Romsdal, Norway. J Neurol Neurosurg Psychiatry 1995;58: 417-421.

26. Strauss D, Shavelle R. Life expectancy of persons with chronic disabilities. J Insur Med 1998;30:96-108.

27. Degenhardt A, Ramagopalan SV, Scalfari A, Ebers GC. Clinical prognostic factors in multiple sclerosis: a natural history review. Nat Rev Neurol 2009;5:672-682.

28. Bronnum-Hansen H, Koch-Henriksen N, Hyllested K. Survival of patients with multiple sclerosis in Denmark: a nationwide, long-term epidemiologic survey. Neurology 1994;44: 1901-1907.

29. Orton SM, Herrera BM, Yee IM, et al. Sex ratio of multiple sclerosis in Canada: a longitudinal study. Lancet Neurol 2006;5:932-936.

30. Le BE. Forecasting continuously increasing life expectancy: what implications? Ageing Res Rev 2012;11:325-328.

31. Ebers GC, Reder AT, Traboulsee A, et al. Long-term follow-up of the original interferon-beta1b trial in multiple sclerosis: design and lessons from a 16-year observational study. Clin Ther 2009;31:1724-1736.

32. Bronnum-Hansen H, Stenager E, Hansen T, KochHenriksen H. Survival and mortality rates among Danes with MS. Int MS J 2006;13:66-71.

33. Marrie RA, Horwitz RI, Cutter G, Tyry T, Vollmer T. Association between comorbidity and clinical characteristics of MS. Acta Neurol Scand 2011;124:135-141.

34. Kantarci O, Siva A, Eraksoy M, et al. Survival and predictors of disability in Turkish MS patients: Turkish Multiple Sclerosis Study Group (TUMSSG). Neurology 1998;51:765-772.

35. Scalfari A, Neuhaus A, Daumer M, Ebers GC, Muraro PA. Age and disability accumulation in multiple sclerosis. Neurology 2011;77:1246-1252.

36. Cottrell DA, Kremenchutzky M, Rice GP, et al. The natural history of multiple sclerosis: a geographically based study: 5: the clinical features and natural history of primary progressive multiple sclerosis. Brain 1999;122:625-639.

37. Osoegawa M, Kira J, Fukazawa T, et al. Temporal changes and geographical differences in multiple sclerosis phenotypes in Japanese: nationwide survey results over 30 years. Mult Scler 2009;15:159-173.

38. Celius EG, Harbo HF, Egeland T, Vartdal F, Vandvik B, Spurkiand A. Sex and age at diagnosis are correlated with the HLA-DR2, DQ6 haplotype in multiple sclerosis. J Neurol Sci 2000;178:132-135.

39. Dyment DA, Ebers GC, Sadovnick AD. Genetics of multiple sclerosis. Lancet Neurol 2004;3:104-110.

40. Willer CJ, Dyment DA, Risch NJ, Sadovnick AD, Ebers GC. Twin concordance and sibling recurrence rates in multiple sclerosis. Proc Natl Acad Sci USA 2003;100:12877-12882.

41. Chao MJ, Herrera BM, Ramagopalan SV, et al. Parent-oforigin effects at the major histocompatibility complex in multiple sclerosis. Hum Mol Genet 2010;19:3679-3689.

42. Kurtzke JF. Rating neurologic impairment in multiple sclerosis: an expanded disability status scale (EDSS). Neurology 1983;33:1444-1452.
43. Nielsen NM, Rostgaard K, Rasmussen S, et al. Cancer risk among patients with multiple sclerosis: a population-based register study. Int J Cancer 2006;118:979-984.

44. Fois AF, Wotton CJ, Yeates D, Turner MR, Goldacre MJ. Cancer in patients with motor neuron disease, multiple sclerosis and Parkinson's disease: record linkage studies. J Neurol Neurosurg Psychiatry 2010;81:215-221.

45. Achiron A, Barak Y, Gail M, et al. Cancer incidence in multiple sclerosis and effects of immunomodulatory treatments. Breast Cancer Res Treat 2005;89:265-270.

46. Bahmanyar S, Montgomery SM, Hillert J, Ekbom A, Olsson T. Cancer risk among patients with multiple sclerosis and their parents. Neurology 2009;72:1170-1177.

47. Handel AE, Ramagopalan SV. Multiple sclerosis and risk of cancer: a meta-analysis. J Neurol Neurosurg Psychiatry 2010;81:1413-1414.

48. Goodin DS, Reder AT, Ebers GC, et al. Survival in MS: a randomized cohort study 21 years after the start of the pivotal IFNbeta-1b trial. Neurology 2012;78:1315-1322.

49. Fredrikson S, Cheng Q, Jiang GX, Wasserman D. Elevated suicide risk among patients with multiple sclerosis in Sweden. Neuroepidemiology 2003;22:146-152.

50. Bronnum-Hansen H, Stenager E, Nylev SE, KochHenriksen N. Suicide among Danes with multiple sclerosis. J Neurol Neurosurg Psychiatry 2005;76:1457-1459.

51. Tremlett H, Zhao Y, Rieckmann P, Hutchinson M. New perspectives in the natural history of multiple sclerosis. Neurology 2010;74:2004-2015.

52. Daumer M, Neuhaus A, Morrissey S, Hintzen R, Ebers GC. MRI as an outcome in multiple sclerosis clinical trials. Neurology 2009;72:705-711.

53. Ebers GC, Heigenhauser L, Daumer M, Lederer C, Noseworthy JH. Disability as an outcome in MS clinical trials. Neurology 2008;71:624-631.

54. Ebers GC, Daumer M, Scalfari A. Surrogate endpoints for EDSS worsening in multiple sclerosis: a meta-analytic approach: measuring disability in relapsing-remitting MS. Neurology 2011;76:1025-1026.

55. Reder AT, Ebers GC, Traboulsee A, et al. Cross-sectional study assessing long-term safety of interferon-beta- $1 \mathrm{~b}$ for relapsing-remitting MS. Neurology 2010;74:1877-1885.

56. Ebers GC, Traboulsee A, Li D, et al. Analysis of clinical outcomes according to original treatment groups 16 years after the pivotal IFNB-1b trial. J Neurol Neurosurg Psychiatry 2010;81:907-912.

57. Goodin DS, Traboulsee A, Knappertz V, et al. Relationship between early clinical characteristics and long term disability outcomes: 16 year cohort study (follow-up) of the pivotal interferon beta-1b trial in multiple sclerosis. J Neurol Neurosurg Psychiatry 2012;83:282-287.

58. Kappos L, Traboulsee A, Constantinescu C, et al. Long-term subcutaneous interferon beta-1a therapy in patients with relapsing-remitting MS. Neurology 2006;67:944-953.

59. Ford C, Goodman AD, Johnson K, et al. Continuous long-term immunomodulatory therapy in relapsing multiple sclerosis: results from the 15-year analysis of the US prospective open-label study of glatiramer acetate. Mult Scler 2010;16:342-350. 